\title{
Nutritional regulation of differentiation and synthesis of an exocytoplasmic deoxyriboendonuclease in Streptomyces antibioticus
}

\author{
Clara G. de los Reyes-Gavilán, Santiago Cal, Covadonga Barbés, Carlos Hardisson and \\ JESUS SÁNCHEZ*
}

Department of Functional Biology, Area of Microbiology, Faculty of Medicine, University of Oviedo, Oviedo, Spain

(Received 8 May 1990; revised 16 August 1990; accepted 17 September 1990)

\begin{abstract}
Streptomyces antibioticus produces a cell-wall-located deoxyriboendonuclease (DNAase) the synthesis of which in submerged and surface cultures is related to the growth rate. DNAase synthesis always preceded aerial mycelium formation in surface cultures. Production of aerial mycelium began at the end of exponential growth or in the early stationary phase; it was absent in cultures grown on nutrient agar/glucose or in media with a high concentration of casein hydrolysate. These nutritional conditions also impaired production of the DNAase. External DNA substrates were not degraded by mycelium producing the DNAase. These observations lead us to suggest a role for the enzyme in the developmental cycle of $S$. antibioticus.
\end{abstract}

\section{Introduction}

Bacteria of the genus Streptomyces have a relatively complex life-cycle, with the production of a substrate ('vegetative') mycelium and an aerial ('reproductive') mycelium. Streptomycetes are of great ecological significance in the soil, and produce a variety of metabolites, of which antibiotics and degradative enzymes are among the most interesting (Williams et al., 1983; Chater \& Hopwood, 1984; Queener \& Day, 1986). Nutrient limitation in Streptomyces has been shown to trigger differentiation and induction of secondary metabolism (Kalakoutskii \& Agre, 1976; Ensign, 1978; Braña \& Demain, 1988). By comparison, rich nitrogen sources which promote high growth rates tend to impede differentiation (Kalakoutskii \& Agre, 1976; Coleman \& Ensign, 1982; Ochi, 1986, 1987).

We (de los Reyes-Gavilán et al., 1988a) have previously described, in Streptomyces antibioticus ATCC 11891 , an unusual exocytoplasmic endo-DNAase located between the cytoplasmic membrane and the cell wall; no other major exocellular or endocellular nuclease activities were detected in this strain. Absence of the enzyme in cells grown in some media, indicated that the synthesis of the enzyme was regulated, and suggested that the DNAase may have other cellular roles besides the restriction of phages under certain circumstances (de los Reyes-Gavilán et al., 1988a). In the present work we have analysed in more detail the control exerted by the culture medium on the synthesis of the nuclease, under conditions not allowing differentiation (submerged cultures) and in conditions permitting differentiation (surface cultures). We show that the growth rate of the culture is the main factor that controls the onset and level of endonuclease synthesis. A possible role of the nuclease in the Streptomyces developmental cycle is suggested.

\section{Methods}

Bacteria. S. antibioticus ATCC 11891, an oleandomycin producer, was used throughout.

Growth media and culture conditions. GAE (glucose/asparagine/yeast extract), NBG (nutrient broth/glucose) and NAG (nutrient agar/glucose) media have been described previously (de los Reyes-Gavilán et al., 1988a). Basal medium (BM) was composed of $0.05 \%$ $\mathrm{MgSO}_{4} .7 \mathrm{H}_{2} \mathrm{O}, 0.05 \% \mathrm{~K}_{2} \mathrm{HPO}_{4}(2.8 \mathrm{mM})$ and $0.001 \% \mathrm{FeSO}_{4} .7 \mathrm{H}_{2} \mathrm{O}$, to which $0 \cdot 1-1 \%$ glucose and $0 \cdot 1-2 \%$ of a nitrogen source (acid hydrolysate of casein, alanine or asparagine) were added, as specified. Synthetic medium (SM) is the basal medium supplemented with $0.5 \%$ glucose, $0 \cdot 1 \%$ asparagine and $0 \cdot 1 \%\left(\mathrm{NH}_{4}\right)_{2} \mathrm{SO}_{4}$. When the $\mathrm{pH}$ of the cultures would otherwise have fallen below 6 , media were buffered with $0 \cdot 1 \mathrm{M}$-TES, $\mathrm{pH} 7.5$; growth and enzyme synthesis were not affected in these conditions. Acid hydrolysate of casein (Hy-case) was purchased from Sigma.

Growth was carried out at $30^{\circ} \mathrm{C}$. For surface cultures, substrate mycelium or substrate mycelium plus aerial mycelium were obtained from agar plates overlaid with cellophane disks (Mendez et al., 1985) by scraping the cellophane with a spatula (de los Reyes-Gavilán et al., $1988 b$ ). When aerial mycelium alone was required (in order to measure DNAase activity), it was collected from several well-developed plates without cellophane, by direct scraping of the agar medium with a spatula. 
Growth measurement. Growth on submerged and surface cultures was determined by homogenization of mycelial suspensions by ultrasonic treatment and measurement of $\mathrm{OD}_{600}$ as described by Braña $e t$ al. (1985). For surface cultures, cellophane-grown mycelium was employed.

DNAase assay in cell-free extracts. Mycelium from submerged and surface cultures was collected at various stages of growth as indicated above. After high-speed centrifugation of sonicated mycelia in the extraction buffer, enzyme activity was determined in the supernatant (de los Reyes-Gavilán et al., 1988a). In order to compare the activity of the different samples, the ratio between the weight of the mycelium sample and the volume of extraction buffer was kept constant $(1: 2$, $w / v)$. The DNAase initially gives discrete bands as hydrolytic products; these are subsequently degraded to short oligonucleotides (de los Reyes-Gavilán et al., 1988a). Thus, the activity was readily followed by direct visualization of the digestion products of $\lambda$ phage DNA $(0.5 \mu \mathrm{g})$ on agarose gel after electrophoresis (de los Reyes-Gavilán et al., $1988 a$ ). One gel unit (U) was defined as the smallest amount of nuclease necessary to complete degradation of $0.5 \mu \mathrm{g}$ of $\lambda$ DNA to short oligonucleotides after $1 \mathrm{~h}$ of incubation at $37^{\circ} \mathrm{C}$.

Glucose and nitrogen measurement. Glucose content in supplemented BM was measured by the method of Somogyi (1952). Ninhydrinpositive compounds were determined by the procedure of Rosen (1957), to estimate amino acid consumption. BM plus glucose initially contained no ninhydrin-reactive substances other than the amino acids employed as nitrogen source. When surface cultures were analysed, one agar plug of constant diameter was cut out from the centre of each plate (containing $30 \mathrm{ml}$ medium) and solubilized as described previously (Braña et al., 1988); the solution obtained was analysed for glucose and amino acid content, as above.

DNA sources. Calf thymus DNA (high molecular mass) was obtained from Boehringer. Herring sperm DNA ('degraded free acid') was purchased from Sigma and was purified before use as a nutrient; DNA was first extracted twice with $50 \mathrm{~mm}-\mathrm{Tris} / \mathrm{HCl}(\mathrm{pH} 8.0)$ saturated phenol (Fluka) followed by two extractions with a mixture of saturated phenol and chloroform $(1: 1, \mathrm{v} / \mathrm{v})$. After a further three extractions with chloroform, the DNA was precipitated with 2 vols ethanol $(95 \%, \mathrm{v} / \mathrm{v})$.

\section{Results}

\section{Control of endonuclease synthesis in submerged cultures}

From data previously obtained with cultures grown in different complex liquid media (GAE, GYM and NBG), it was concluded that formation of the $S$. antibioticus DNAase was affected by the culture medium used (de los Reyes-Gavilán et al., 1988a). No attempt was made in that earlier work to elucidate which factor(s) caused DNAase activity to be lower in NBG and GYM media (GYM medium was the CC medium described in Sánchez et al., 1985) than in GAE medium. To establish if a rich nitrogen source could interfere with synthesis of the enzyme in submerged cultures, we first tested the effect of a mixture of amino acids (Hy-case) in a synthetic medium (SM) suitable for enzyme synthesis. As shown in Fig. 1, S. antibioticus produced endonuclease in SM from the middle of the exponential growth phase,
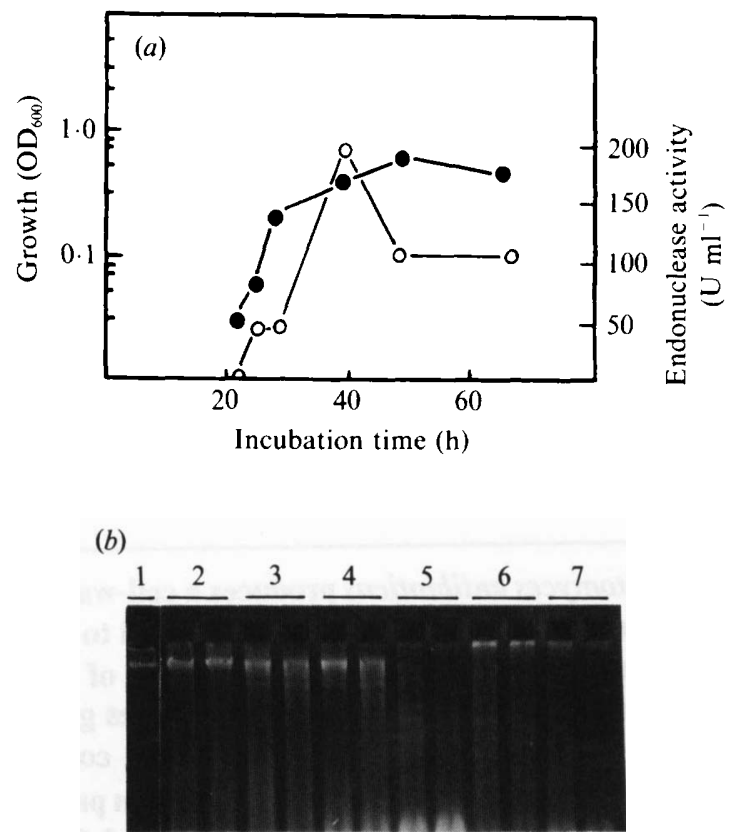

Fig. 1. Growth curve and endonuclease activity in $S$. antibioticus grown in liquid SM. (a) Growth (e) and DNAase activity, (O). (b) $\lambda$ DNA $(0.5 \mu \mathrm{g})$ alone (lane 1$)$ and DNAase activity in the mycelia grown for 21 (lanes 2), 24 (lanes 3), 27 (lanes 4), 39 (lanes 5), 48 (lanes 6), and 65 $\mathrm{h}$ (lanes 7). The pairs of lanes contain DNA $(0.5 \mu \mathrm{g})$ digested with crude extract for $20 \mathrm{~min}$ (left) and $60 \mathrm{~min}$ (right).

although higher enzyme levels were detected in the stationary phase. Remarkably, endonuclease synthesis was suppressed when this medium was supplemented with $1 \%$ Hy-case (not shown).

The effect of Hy-case as the sole nitrogen source was studied further. S. antibioticus was cultivated in BM supplemented with $1 \%$ glucose and $\mathrm{Hy}$-case at 0.1 or $1 \%$. Growth rates in the exponential phase were considerably higher in BM supplemented with $\mathrm{Hy}$-case than in SM $\left(K=1.90 \mathrm{~h}^{-1}, 1.38 \mathrm{~h}^{-1}\right.$ and $0.27 \mathrm{~h}^{-1}$, for $0.1 \% \mathrm{Hy}$-case, $1 \% \mathrm{Hy}$-case and SM, respectively). Enzyme formation was more restricted in comparison with SM, occurring in a short period at the end of the exponential phase or in the early stationary phase on either $0.1 \% \mathrm{Hy}$-case (Fig. 2) or $1 \% \mathrm{Hy}$-case (data not shown). Also, in the latter culture the activity was almost undetectable. The shift from exponential to stationary phase could have been caused by nitrogen source depletion in the medium with $0.1 \% \mathrm{Hy}$-case (Fig. 2), but not in that with $1 \% \mathrm{Hy}$-case, where the beginning of the stationary phase was probably due to starvation for some other nutrient. Thus, the decrease in growth rate, by itself, could stimulate the production of the nuclease. 


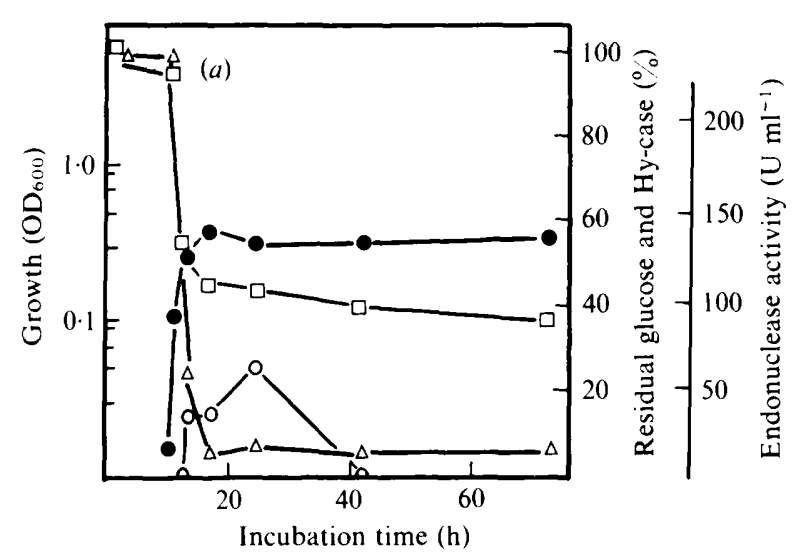

(b)

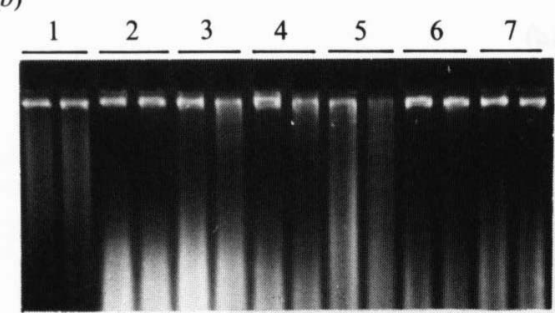

Fig. 2. Growth curve, glucose and nitrogen consumption and endonuclease activity in cell-free extracts of $S$. antibioticus grown in liquid BM plus $1 \%$ glucose and $0.1 \%$ Hy-case. (a) Growth $(\bullet)$, residual glucose $(\square)$ and amino acid $(\triangle)$ concentration, and DNAase activity (O). (b) DNAase activity in mycelia grown for 10 (lanes 1 ), 11 (lanes 2), 13 (lanes 3), 17 (lanes 4), 25 (lanes 5), 42 (lanes 6) and 73 h (lanes 7). Pairs of lanes as in Fig. 1.

Effect of individual amino acids on endonuclease synthesis in submerged cultures

In BM plus glucose, alanine promoted a high growth rate, whereas with asparagine, the growth rate was noticeably lower $\left(K=0.47 \mathrm{~h}^{-1}\right.$ for $0.1 \%$ alanine; $K=0.16 \mathrm{~h}^{-1}$ and $0.10 \mathrm{~h}^{-1}$ for $0.1 \%$ and $1 \%$ asparagine, respectively). When present in $\mathrm{BM}$, these amino acids were not utilized by $S$. antibioticus as carbon sources, and they did not affect the assay of in vitro enzyme activity. Alanine or asparagine concentrations higher than $1 \%$ were not employed in submerged cultures because such concentrations caused early lysis of hyphae.

In $\mathrm{BM}$ supplemented with $1 \%$ glucose plus $0.1 \%$ alanine, as sole nitrogen source, enzyme activity was detected from the end of the exponential growth phase; the transition to stationary phase was caused by the exhaustion of the amino acid (Fig. $3 a, b$ ). With a higher concentration of alanine $(1 \%)$ neither amino acid nor the glucose was exhausted by the time nuclease was produced (not shown). In BM plus $1 \%$ alanine and $0.1 \%$ glucose, when the carbon source quickly became limiting, there was an early reduction in the initial growth rate of the culture $\left(K=0.46 \mathrm{~h}^{-1}\right)$, accompanied by the start of enzyme synthesis, which continued throughout the stationary phase, without alanine consumption (Fig. 3c,d).

When asparagine (at 0.1 or $1 \%$ ) was employed as nitrogen source, the growth rate, as already stated, was noticeably lower than for alanine-supplemented medium, and enzyme synthesis started in the exponential growth phase (Fig. 4). As in SM, DNAase activity increased at the end of the exponential phase or in the early stationary phase. The nitrogen and carbon sources were not depleted in this medium.

Different concentrations of glucose in SM $(0.5-1 \%)$ or its absence in NBG did not modify the pattern of enzyme synthesis (data not shown).

These observations indicated that endonuclease synthesis in submerged cultures is not dependent on the depletion of a particular nitrogen or carbon source, and suggested a relationship between growth rate and enzyme synthesis. This relationship was also evident in media GAE $\left(K=0.30 \mathrm{~h}^{-1}\right)$, where endonuclease synthesis occurred in the exponential phase, and NBG $\left(K=0.73 \mathrm{~h}^{-1}\right)$, where synthesis was not detected (de los Reyes-Gavilán et al., 1988a).

\section{Endonuclease synthesis in surface cultures}

Media with the same nitrogen and carbon sources as those used in the submerged cultures were tested.

With alanine (at $0.1 \%$ or $1 \%$; higher concentrations caused a noticeable lysis of surface mycelia), growth rates were lower than in liquid media (Table 1) and nuclease synthesis started in the early exponential growth phase without exhaustion of nitrogen and carbon sources (Fig. 5). This is contrary to what occurred in liquid media (Fig. 3), where a decrease of the high initial growth rate was necessary for endonuclease synthesis. With asparagine, growth rates were similar to those in submerged culture (Table 1); at all concentrations tested $(0 \cdot 1,1$ and $2 \%$, enzyme synthesis began in the exponential growth phase before the glucose of amino acid were fully consumed (Fig. 6). In BM plus $0 \cdot 1 \% \mathrm{Hy}$ case, the growth rate was higher than in BM supplemented with asparagine or alanine (Table 1) and nuclease synthesis started, as in submerged cultures, at the end of the exponential phase when the nitrogen source was limiting (data not shown).

Remarkably, DNAase activities of mycelia on solid media were noticeably higher than those in the corresponding liquid media. On the other hand, activity was very low on NAG or in BM plus $1 \%$ glucose and $2 \% \mathrm{Hy}-$ case (not shown), in which the nitrogen source was not consumed when the stationary phase started. All these results were consistent with nuclease production in surface cultures being mainly controlled by growth rate, as in liquid media. 


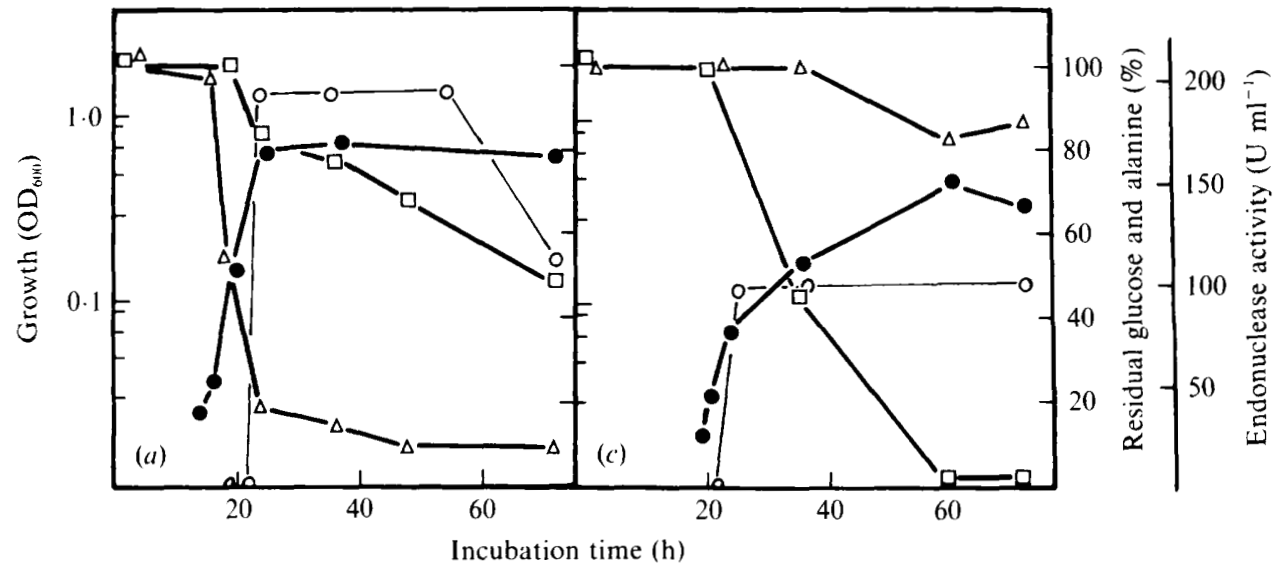

(b)

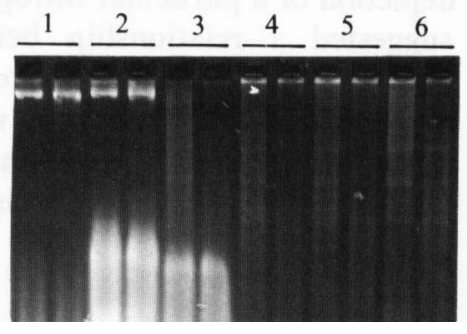

(d)

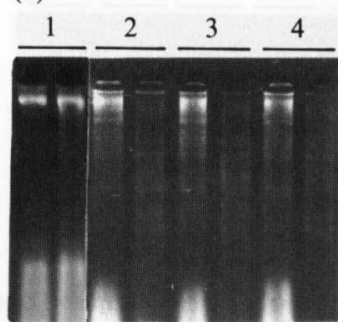

Fig. 3. Growth curve, glucose and nitrogen consumption and endonuclease activity in cell-free extracts of $S$. antibioticus grown in liquid BM plus glucose and alanine as the sole nitrogen source. (a) BM plus $1 \%$ glucose and $0.1 \%$ alanine; (c) BM plus $0.1 \%$ glucose and $1 \%$ alanine: growth $(\bullet)$, residual glucose $(\square)$ and alanine $(\triangle)$ concentration and DNAase activity $(O)$. (b) DNAase activity in mycelia grown in BM plus $1 \%$ glucose and $0.1 \%$ alanine for 16 (lanes 1), 19 (lanes 2), 24 (lanes 3), 36 (lanes 4), 48 (lanes 5) and $72 \mathrm{~h}$ (lanes 6). (d) DNAase activity in mycelia grown in BM plus $0.1 \%$ glucose and $1 \%$ alanine for 21 (lanes 1), 24 (lanes 2), 36 (lanes 3 ), and $72 \mathrm{~h}$ (lanes 4). Pairs of lanes as in Fig. 1.

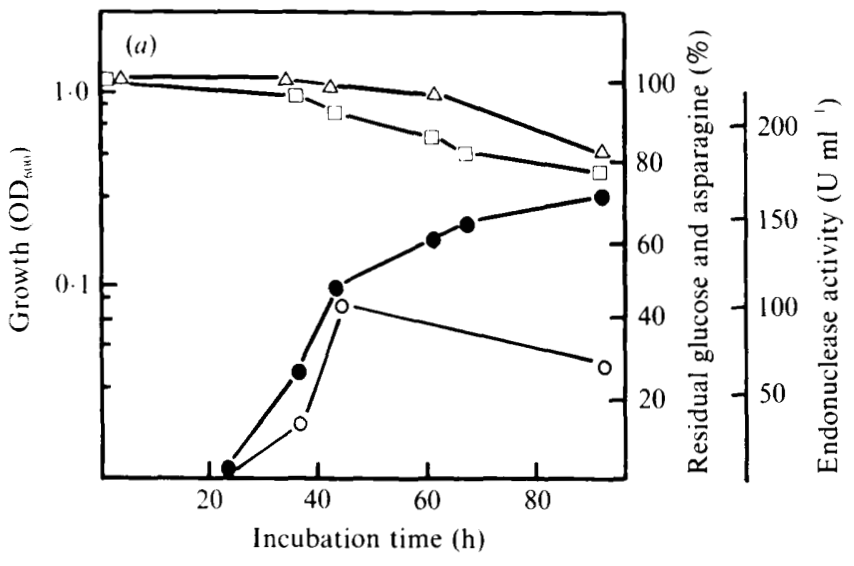

\section{Differentiation on agar media}

The appearance of aerial mycelium in surface cultures in all cases coincided with the end of the exponential growth phase or with the early stationary phase (Figs 5 and 6). Thus, the nuclease was detected in substrate mycelium before there were macroscopic or microscopic signs of differentiation; on the other hand, no nuclease activity was detected in the aerial mycelium. In addition, aerial mycelium formation was almost suppressed by high concentrations of $\mathrm{Hy}$-case and in NAG medium, but not in BM with $2 \%$ asparagine (Table 1). Those are, as shown above, the conditions that repressed the synthesis of the DNAase. Sporulation was observed only when the nitrogen source was totally consumed, i.e. media with $0.1 \%$ alanine, $0.1 \%$ asparagine (Figs 5 and 6 ) or $0.1 \%$ Hy-case, and in GAE (Table 1). The glucose

Fig. 4. Growth curve, glucose and nitrogen consumption and endonuclease activity in cell-free extracts of $S$. antibioticus grown in liquid BM plus $1 \%$ glucose and $0.1 \%$ asparagine. (a) Growth $(\bullet)$, residual glucose $(\square)$ and asparagine $(\triangle)$ concentration, and DNAase activity (O). (b) DNAase activity in mycelia grown for 36 (lanes 1), 43 (lanes 2) and $92 \mathrm{~h}$ (lanes 3). Pairs of lanes as in Fig. 1. 


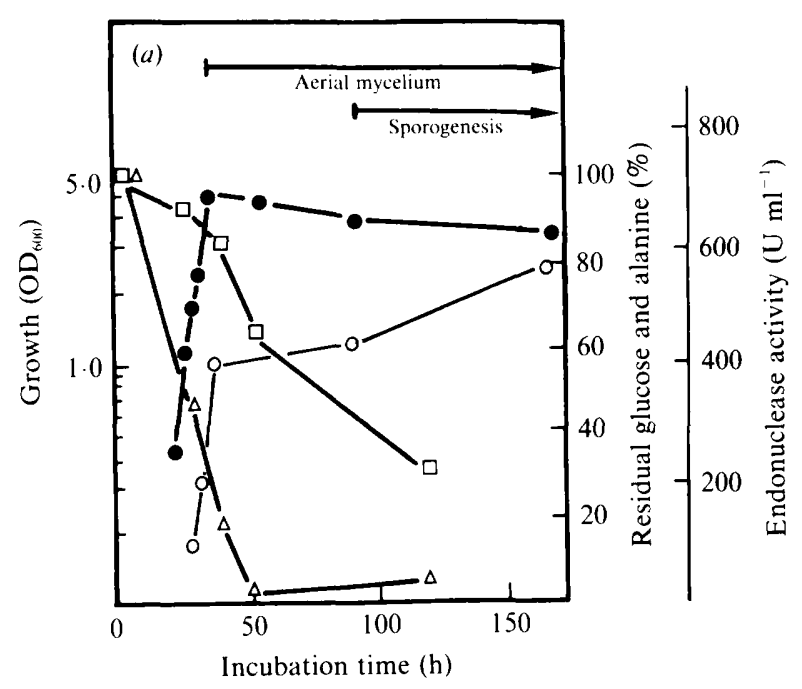

(b)

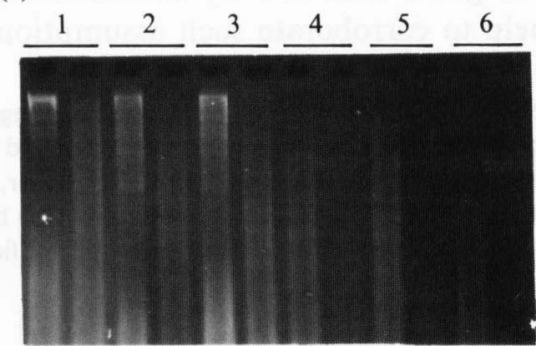

Fig. 5. Growth curve, glucose and nitrogen consumption, differentiation and endonuclease activity in cell-free extracts of $S$. antibioticus grown on solid BM plus $1 \%$ glucose and $0.1 \%$ alanine. (a) Growth $(\bullet)$, residual glucose $(\square)$ and alanine $(\triangle)$ concentration, and DNAase activity (O). (b) DNAase activity in mycelia grown for 26 (lanes 1), 30 (lanes 2), 33 (lanes 3), 38 (lanes 4), 89 (lanes 5) and 167 h (lanes 6). Pairs of lanes as in Fig. 1.

concentration itself did not seem to influence the capacity to sporulate under the conditions studied, because in media with $0.1 \%$ glucose and $1 \%$ alanine (Table 1) or asparagine (not shown), where the carbon source was quickly exhausted, sporulation did not occur.

\section{Degradative function of nuclease is not related to external substrates}

A possible role of the nuclease of $S$. antibioticus could be the degradation of foreign external DNA, the digestion products being utilized as a source of metabolites. DNA was therefore tested as a nutrient source in $\mathrm{BM}$ plus $0.5 \%$ glucose. No growth was obtained with high molecular mass DNA (undegraded calf thymus DNA at $0.1 \%$ ) when an inoculum of spores or DNAase-active mycelium (from GAE or SM) was employed. However, growth was good on partially degraded herring sperm DNA.

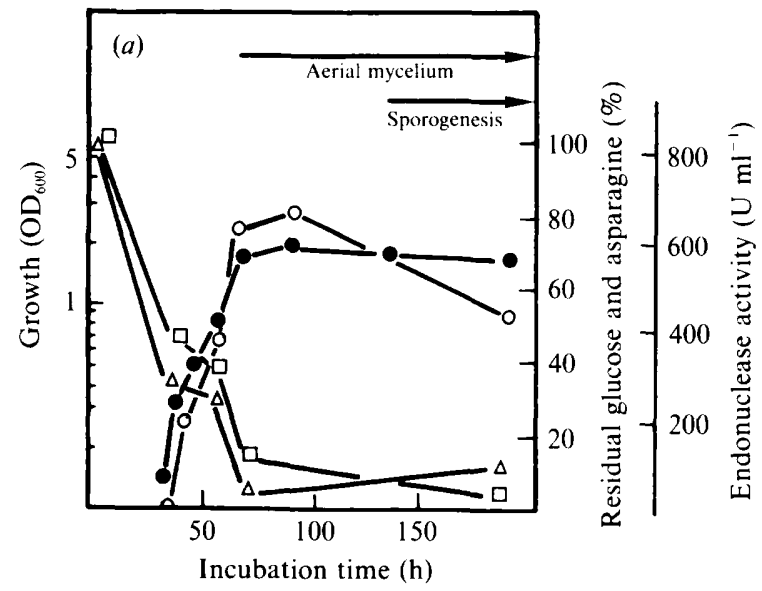

(b)

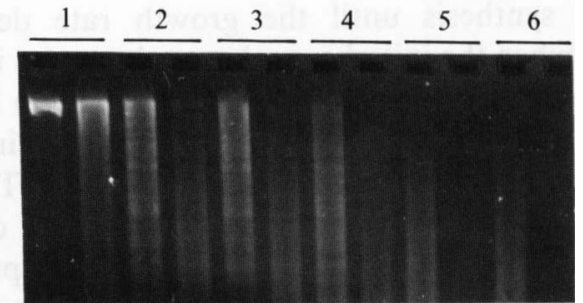

Fig. 6. Growth curve, glucose and nitrogen consumption, differentiation and endonuclease activity in cell-free extracts of $S$. antibioticus grown on solid BM plus $1 \%$ glucose and $0.1 \%$ asparagine. (a) Growth $(\bullet)$, residual glucose $(\square)$ and asparagine $(\triangle)$ concentration and DNAase activity $(O)$. (b) DNAase activity in mycelia grown for 33 (lanes 1), 38 (lanes 2), 57 (lanes 3), 65 (lanes 4), 89 (lanes 5) and $172 \mathrm{~h}$ (lanes 6). Pairs of lanes as in Fig. 1.

Table 1. Growth rates, aerial mycelium $(A M)$ formation and sporulation of $S$. antibioticus obtained from different surface cultures

\begin{tabular}{|c|c|c|c|}
\hline Medium & $\begin{array}{l}\text { Growth } \\
\text { rate }\left(\mathrm{h}^{-1}\right)^{*}\end{array}$ & $\mathrm{AM} \dagger$ & Sporulation $\ddagger$ \\
\hline GAE & 0.32 & + & + \\
\hline $\begin{array}{c}B M+\text { glucose }(1 \%) \text { and } \\
\text { asparagine }(0.1 \%)\end{array}$ & $0 \cdot 17$ & + & + \\
\hline $\begin{array}{c}\mathrm{BM}+\text { glucose }(1 \%) \text { and } \\
\text { asparagine }(1 \%)\end{array}$ & $0 \cdot 14$ & + & - \\
\hline $\begin{array}{c}\mathrm{BM}+\text { glucose }(1 \%) \text { and } \\
\text { asparagine }(2 \%)\end{array}$ & 0.08 & + & - \\
\hline $\begin{array}{l}\text { BM }+ \text { glucose }(1 \%) \text { and } \\
\text { alanine }(0.1 \%)\end{array}$ & $0 \cdot 16$ & + & + \\
\hline $\begin{array}{l}\mathrm{BM}+\text { glucose }(1 \%) \text { and } \\
\text { alanine }(1 \%)\end{array}$ & $0 \cdot 19$ & + & - \\
\hline $\begin{array}{l}\text { BM }+ \text { glucose }(1 \%) \text { and } \\
\text { alanine }(1 \%)\end{array}$ & $0 \cdot 12$ & + & - \\
\hline NAG & $0 \cdot 71$ & $+1-$ & - \\
\hline $\begin{array}{c}\text { BM }+ \text { glucose }(1 \%) \text { and } \\
\text { Hy-case }(0.1 \%)\end{array}$ & $1 \cdot 32$ & + & + \\
\hline
\end{tabular}

* Growth rate $=2.303\left(\log \mathrm{OD}_{2}-\log \mathrm{OD}_{1}\right) / t_{2}-t_{1}$, where $t_{1}$ and $t_{2}$ are points (in $h$ ) of the interval of exponential phase where the growth rate was measured. Values are the mean of at least two different experiments.

† Scored after $7 \mathrm{~d}$ incubation: +, present; -, absent; +/- sparse.

$\ddagger$ Scored after $7-10 \mathrm{~d}$ incubation: + , present; - , absent.

$\S$ Glucose and asparagin concentrations in this medium were $1 \%$ and $0.1 \%$ respectively. 


\section{Discussion}

Although the genus Streptomyces is considered to be a good producer of nucleases including exocellular DNAases requiring $\mathrm{Mg}^{2+}$ (Yanagida \& Ogawara, 1980; Chater, 1984), there have been no studies on the regulation of nuclease production.

Our earlier results suggested that synthesis of the endonuclease of $S$. antibioticus was influenced by the growth medium (de los Reyes-Gavilán et al., 1988a); to investigate this further, the production of the enzyme in several media was studied. The commencement and intensity of nuclease synthesis were linked to the growth rate of the culture: high growth rates (such as those reached in media with alanine or Hy-case) retarded nuclease synthesis until the growth rate decreased, whereas when the initial growth was slower (as in media with asparagine as sole nitrogen source, or in SM) the nuclease was produced earlier but activity levels increased when the culture entered the stationary phase. The same type of regulation also occurred in surface cultures; moreover, whereas asparagine and Hy-case promoted similar growth rates as those in liquid media, growth with alanine was slower, and the nuclease appeared as early as the exponential phase. Activity levels in solid media were distinctly higher than those in liquid media.

Sporulation was linked to exhaustion of the nitrogen source in $S$. antibioticus, as previously shown by Braña $e t$ al. (1988), using GAE medium. As described in other Streptomyces species (Ochi, 1986, 1987), the carbon source does not seem to influence this process. Furthermore, synthesis of the DNAase always preceded the formation of aerial mycelium, and although the amino acid nitrogen source was not exhausted, the appearance of aerial mycelium coincided with a change in the growth phase. Thus, some type of common regulation of both processes could occur; sporulation could also respond to additional regulatory circuits, such as complete exhaustion of the nitrogen source. Further evidence of a linkage between DNAase production and aerial mycelium formation is the fact that all mutants obtained from $S$. antibioticus lacking nuclease activity are also defective in AM (de los Reyes-Gavilán and others, unpublished). The failure of intact cells to utilize exogenous high molecular mass DNA indicates that the role of the endonuclease is not to degrade external DNA substrates. Chromosomal DNA from $S$. antibioticus is sensitive to the DNAase (de los Reyes-Gavilán et al., 1988a); thus there is presumably no protection mechanism in vivo other than the exocytoplasmic location of the enzyme. Therefore, we postulate that the DNAase of $S$. antibioticus may play a role in the development of aerial mycelium, furnishing nucleotides from the DNA of substrate mycelium. The 'parasitic' behaviour of aerial mycelium with respect to the substrate mycelium has already been proposed (Chater, 1984; Mendez et al., 1985 ) and experimentally supported in S. antibioticus on the basis of the 'turnover' of the proteins of the substrate mycelium that occurs to form the aerial mycelium (Mendez et al., 1985). It is also interesting to note that whereas Granozzi et al. (1990) showed that a decline of nucleic acid and protein synthesis preceded differentiation in $S$. coelicolor A3(2), the activity of the DNAase in $S$. antibioticus increased during the exponential phase prior to aerial mycelium formation. We have recently shown in S.glaucescens and other species of Streptomyces the presence of DNAases with analogous location and regulation to the DNAase from $S$. antibioticus (Aparicio et al., 1988, and unpublished work). It is possible that all these enzymes play a common role in Streptomyces development. Characterization of the enzymes and cloning of genes followed by insertional mutagenesis should help to corroborate such assumptions.

We thank Dr K. F. Chater for his helpful suggestions on the manuscript. C. G. de los Reyes-Gavilán was supported by a fellowship of the Plan de Formacion de Personal Investigador, Ministerio de Educacion y Ciencia, Spain. The work was supported by grant BI0890014 from the Plan Nacional de Investigacion Cientifica y Desarrollo Tecnológico, CICYT, Spain.

\section{References}

Aparicio, J. F., de los Reyes-Gavilán, C. G., Barbés, C., HARDisSON, C. \& SÁNCHEZ, J. (1988). A non-specific deoxyribonuclease with restriction function in Streptomyces glaucescens. Journal of General Microbiology 134, 2345-2351.

Braña, A. F. \& Demain, A. L. (1988). Nitrogen source control of antibiotic biosynthesis in actinomycetes. In Nitrogen Source Control of Microbial Processes, pp. 99-119. Edited by S. Sanchez Esquivel. Boca Raton, Florida: CRC Press.

Braña, A. F., Wolfe, S. \& Demain, A. L. (1985). Ammonium repression of cephalosporin production by Streptomyces clavuligerus. Canadian Journal of Microbiology 31, 736-743.

Braña, A. F., Mendez, C., Diaz, L. A., Manzanal, M. B. \& HaRdisson, C. (1988). Glycogen and trehalose accumulation during colony development in Streptomyces antibioticus. Journal of General Microbiology 132, 1319-1326.

ChATER, K. F. (1984). Morphological and physiological differentiation in Streptomyces. In Microbial Development (Monographic Series 16), pp. 89-115. Edited by R. Losick \& L. Shapiro. Cold Spring Harbor, NY: Cold Spring Harbor Laboratory.

Chater, K. F. \& Hopwood, D. A. (1984). Streptomyces genetics. In The Biology of the Actinomycetes, pp. 229-286. Edited by M. Goodfellow, M. Mordarski \& S. T. Williams. London: Academic Press.

Coleman, R. H. \& ENSIGN, J. C. (1982). Regulation of formation of aerial mycelia and spores of Streptomyces viridochromogenes. Journal of Bacteriology 149, 1102-1111.

ENSIGN, J. C. (1978). Formation, properties and germination of actinomycete spores. Annual Review of Microbiology 32, 185-219.

Granozzi, C., Billetta, R., Passantino, R., Sollazzo, M. \& Puglia, M. (1990). A breakdown in macromolecular synthesis preceding differentiation in Streptomyces coelicolor A3(2). Journal of General Microbiology 136, 713-716. 
KalakoutSkiI, L. V. \& AGRE, N. S. (1976). Comparative aspects of development and differentiation in actinomycetes. Bacteriological Reviews 40, 469-524.

Mendez, C., Braña, A. F., Manzanal, M. B. \& Hardisson, C. (1985). Role of substrate mycelium in colony development in Streptomyces. Canadian Journal of Microbiology 31, 446-450.

OCHI, K. (1986). A decrease in GTP content is associated with aerial mycelium formation in Streptomyces MA 406-A-1. Journal of General Microbiology 132, 299-305.

OCHI, K. (1987). Metabolic initiation of differentiation and secondary metabolism by Streptomyces griseus: significance of the stringent response (ppGpp) and GTP content in relation to A factor. Journal of Bacteriology 169, 3608-3616.

QUEENER, S. W. \& DAY, L. E. (1986). Antibiotic-producing Streptomyces. In The Bacteria, vol. 9, pp. 355-401. London: Academic Press.

de los Reyes-Gavilán, C. G., Aparicio, J. F., Barbés, C., Hardisson, C. \& SÁnchez, J. (1988a). An exocytoplasmic endonuclease with restriction function in Streptomyces antibioticus. Journal of Bacteriology 170, 1339-1345. de los Reyes-Gavilán, C. G., Aparico, J. F., Barbés, C., Hardisson, C. \& SÁNCHEZ, J. (1988b). Adsorption capability determines phage plaque size on Streptomyces antibioticus producing endodeoxyribonuclease. FEMS Microbiology Letters 56, 301-306.

RoseN, H. (1957). A modified ninhydrin colorimetric analysis for aminoacids. Archives of Biochemistry and Biophysics 67, 10-15.

Sánchez, J., Barbés, C., Hernandez, A., de los Reyes-Gavilán, C. G. \& HARDISSON, C. (1985). Restriction-modification systems in Streptomyces antibioticus. Canadian Journal of Microbiology 31, 942 946.

SOMOGYI, M. (1952). Notes on sugar determination. Journal of Biological Chemistry 190, 519-527.

Williams, S. T., Goodfellow, M., Alderson, G., Wellington, E. M. H., Sneath, P. H. A. \& SACKIN, M. J. (1983). Numerical classification of Streptomyces and related genera. Journal of General Microbiology 129, 1748-1813.

Yanagida, T. \& Ogawara, H. (1980). Deoxyribonucleases in Streptomyces. Journal of Antibiotics 33, 1206-1207. 